\title{
Investigation of Relationship between the Type D Personality and Locus of Control and Predicting Its Addiction Vulnerability
}

\author{
Mehdi Khodabakhshi \\ Departmant of Psychology, Lorestan University, Khorram Abad, Iran
}

Fazlolah Mirdrikvand

Departmant of Psychology, Lorestan University, Khorram Abad, Iran

Masoumeh Abdollahi

MA in General Psychology, Department of Psychology, Semnan Branch, Semnan University, Semnan, Iran Corresponding Author Email: msj5831@yahoo.com

\section{Mina Sadat Mirshoja}

Neuromuscular Rehabilition Research Center, Semnan University of Medical Science, Semnan, Iran

\author{
Doi:10.5901/mjss.2016.v7n4s1p83
}

\section{Abstract}

This research studied on the relationship between the type $D$ personality and source control and predicting its addiction vulnerability. Its aim is to achieve a specific type personality and source control which can predict the addiction vulnerability. This study is descriptive and is done by correlation method to predict and investigate the relationship between the variables. Its statistical population included all active duty forces serving in a service unit. 50 persons were selected randomly. Data was collected by 3 questionnaires of identifying people who are at risk of addiction, type D personality and Rotter's locus of control. The first questionnaire designed by Anisi (1392) includes 4 subscales of depression and helplessness, positive attitude to drugs, anxiety and fear and high sensation seeking. Type D personality questionnaire was designed by Denowelt in 1998 to measure the characteristics associated with type $D$ personality. The third questionnaire was provided to assess the individual's generalized expectations of internal control and external reinforcement. This study's results showed that (i) there is a significant relationship between depression and sensation seeking and negative sentiment and also between positive attitude to drugs and sensation seeking; (ii) there is a negative relationship between the positive attitude to drugs and internal locus of control and also between anxiety and fear and sensation seeking and internal locus of control; and also (iii) there is a positive and significant relationship between addiction vulnerability and type $D$ personality. Also, according to the regression analysis, addiction vulnerability of person can be predicted by type $D$ personality. There is an inverse relationship between the locus of control and addiction vulnerability. Given to the relationship between the personality types and also external locus of control with addiction vulnerability, people can be foster to the internal locus of control by necessary training on necessary skills of people and also probability of the increase of people's addiction vulnerability can be increased by developing a healthy personality type.

Keywords: addiction vulnerability, type $D$ personality and locus of control

\section{Introduction}

Drug abuse is one of the important healthy, social and economic problems in many countries. The results showed that drug addiction is a multi-faceted or multi-factor and various psychological, social, cultural and genetic factors are involved in it (Kaplan \&Sadoc, 2003). Addiction is a kind of social damage that roots in chronic deprivation and exclusion of individuals and specific groups in various communities and imposes a huge cost to society (Ghazinezhad \& Solanpour, 2009; Saah, 2005). There are different reasons for the tendency of drugs. Some people abuse drugs to be accepted in a society and some others try to portray themselves more grown and larger (Abolghasemi et al., 2009). The characteristics of personality are considered as the important factors of etiology in the tendency to risky behaviors such as smoking, using alcohol and drugs and unsafe sexual activities (Polimeni and collegue, 2010). In the viewpoint of psychology, 
people with drug abuse have a vulnerable personality characteristic (Bond, 2005). Personality characteristics of drug addicts is not simply due to drugs but also drug addicts, before addiction, had more mental health and personality disorders which would be intensified destructively after addiction, so, their problem is not only drugs abuse, but, in fact the interrelationship between their personalities and addiction (Ketabi et al., 2009). Personality structure of some people is more favorable than others to accept addiction (Gorgani, 1990).Addiction is a violent bondage to drug that makes people and their individual and social behaviors dependent on itself physically and psychologically and influences on their all individual and social behaviors. Today, addiction as the most important social damage has invaded the human society. Drug abuse has always caused more problems such as the loss of public health, increase of deaths, family and social damages, loss of employment and training opportunities and increased the rates of involvement with the criminal justice system, creating a cycle of drug use, and continuation of the damages and their emergences in subsequent generations which associated with the range of human life. Tendency to drug abuse is terminologically defined as people's beliefs and attitudes about drug use and its positive or negative results (Boles \& Miotto, 2003; Logan and colleague, 2002; Erickson, 1985). There is a direct relationship between the tendency to drug abuseand people's attitude such as their understanding of the legality and social acceptance of drugs, disadvantages caused by drug abuse and unpleasant states and consequences of drug abuse (Sarvela\&McClendon, 1988). Given that drug abuse is a complex issue with many dimensions, any actions and interferences in this require extensive actions and researches. Nicholson and colleague (1996) wrote: "Prevention of drug abuse like as disease prevention requires the identification of causes and factors involved in it". Based on that it is observed that the most addicts has returned to drugs abuse repeatedly and continuously and their inabilities to quit drugs abuse, it is discussed for researchers that drugs abuse should be rooted in the full consistency and ancient structure that has determinant effects on behavior (Walton \& Roberts, 2004).

McCrae \& Costa (2007) defined the characteristics of personality as the various dimensions of individual differences in the tendency to demonstrate stable patterns of thought, feeling and action. Type D personality has two components of negative affectivity and social inhibition. Negative affectivity is characterized by tending to express negative emotions. People with high negative affectivity, regardless of their positions, tend to experience negative emotions more than others at all times (Denollet, 1998). Social inhibition is characterized by stable tendency to inhibit the emotional and behavioral experiences in stable interactions to inhibit the emotional and behavioral experiences in social interactions. People with high social inhibition have more tendencies to avoid the negative reaction of others by controlling self-expression amply (Emonsa, Mejier\&Denollet, 2007).

Rotter's social learning theory deals with our beliefs about the source of reinforcement. Its research showed that some people think that reinforcement depends on their behaviors; it says that these people have internal locus of control. Othersbelievethat reinforcement depends on external forces; it says that they have external locus of control. These two control bases have different effects on behaviors. For people with external locus of control, their capabilities and actions have little impact on the reinforcement that they receive, therefore, they attempt low or don't try to change or improve their positions. People, who have internal locus of control, think that they are responsible for their own lives and act accordingly.Rutter's research has shown that individuals with internal locus of control are physically and mentally healthier than those with external locus of control. These people usually have lower blood pressure, less heart attack and lower anxiety and depression. They get better grades in school and they believe that have more choices in life. They are socially more skilled and famous and have more self-esteem than those with external locus of control. In addition, Rotter's research showed that the locus of control is formed in childhood through the way that parents or caregivers treat with a child. The parents of children with internal locus of control are more supporter than the parents of children with external locus of control and buy more awards to develop their children (provide positive reinforcement), they are stability to establish discipline, and also have non-authoritarian attitudes (Seif, 1378).

The results of studies showed that there is a direct and significant relationship between the personality factors and tendency to drugs abuse (Aadroum, Nikmanesh, Bakhshani, 2010). In one study, it was determined that the consumers of opium have 14.9 percent of anxiety, 11.6 percent of depression, 10.5 percent of a schizoid personality, 10.1 percent of mental weakness and 10.1 percent of antisocial personality. Also, in the consumers of heroin, the highest rates of personality characteristics are related to anxiety(17.6\%), depression (14.4\%) and antisocial personality (14.4\%) (Asarian, Omidi \& Akbari, 2000). On the other hand, the clinical scale of antisocial personality and depression among injecting drug users havemore frequency than other scales (Sepehrmanesh, Ahmadvand, Ghoreishi \& Mousavi, 2008). The results of Robertsand zing's study showed that drug dependence is often associated with anxiety disorders. In study by Macdonald,wells \& wild (1999), four factors of access to drugs, friends and colleagues pressures,dangerous job have significant relationship with addiction (Macdonald et al., 1999). Also, Cirakoglu OC, Isin G. (2005) found that there was a correlation between sensation seeking and drugs trend. Study performed in Iran showed that people with sensation seeking are ready to have a high addiction (Zargar, Najarian \& Naemi, 2008). The studies showed that personality 
characteristics are important etiological factors in the trend of high-risk behaviors such as smoking, alcohol consumption, drug abuse and unsafe sexual activity (Polimeni, Moore \& Gruenert, 2010, Stefansson \& Hesse, 2008, Ball \& collegue, 2006, Meyer TD, Hoffman,2005, Kornor H, Nordvik, 2007, McCrae \& Costa, 2007).Salehi (2001) conducted a study with the aim of investigating the predisposing personality characteristics of addiction and personality characteristics affecting on relapsing after treatment. In this study, he studied 108 addicts by 5 -factor personality test, the results showed that two personality characteristics of high neuroticism and low conscientiousness have had important roles in the risk and repeated relapse after treatment. The results of a study showed that addiction in women has a more hidden form than men (Najari, 2008). Also, Weijersandcollegues' study (2003) suggested the high levels of neuroticism and incompatibilityand low level of extraversionin addicted women.Kornor H, Nordvik (2007) studied on the personality factor and drugs abuse and resulted that persons addicted to opium get low grades in extroversion and openness. Terracciano\&Costa (2004) referred that there is a relationship between drugs abuse and personality factors of high neuroticism and low conscientiousness. McCann (2005) found that there is a negative correlation between the conscientiousness, openness and drugs abuse in his study. In a study in Iran, it was concluded that there are positive significant relationships between the trend of drugs abuse and the personality factors of neuroticism and extraversion and also, there are negative relationships between drugs abuse and conscientiousness and incompatibility (Bahadori\&Khanjani, 2011).Lefcourt (1982) found that people with internal locus of control have more adapted skills in relation to their community. Also, self-destructive behaviors such as smoking, alcohol use and drug addiction are seen less in them (Almasi, 1377). In a polit study, Cheraghi (1389) showed that group counseling and life skills training causes the change of external locus of control to the internal locus of control and the reinforcement of negative attitude towards drugs abuse.

\section{Methodology}

This study is descriptive and correlation method was used to predict and study the relationships of the variables. The statistical population included all active duty forces serving in a service unit. 50 persons were selected randomly. To perform the study, before the completion of desired measures by respondents, at first, researchers provided an explanation about the aim of study and the method of complementing applied measures and then the measures were completed by samples.

Tools of collecting dataThe tools of this study were three questionnaires which were described as follows:

1. The questionnaire of identifying people who are at risk of addiction: this questionnaire was performed by Anisi J. (1392). It has 4 subscales of depression and helplessness, positive attitude to drugs, anxiety and fear and high sensation seeking which is scored by Likert method. The coefficients of its reliability and validity were obtained 0.97 and 0.75by Cronbach's alpha method respectively (Anisi, Bahadori\&Jahanbakhshi, 2013).

2. The questionnaire of type D personality: It was designed by Denowelt in 1998 to measure the characteristics associated with type D personality. It has 14 items that are scored on a five-point Likert method. It has two subscales of negative affectivity and social inhibition. Denowelt reported that the Cronbach's alpha correlations of the reliability of negative affectivity and social inhibition were obtained 0.88 and 0.86 . Also, Bagherian \& Bahrami (1389) reported that the reliability of negative affectivity and social inhibition were obtained 0.86 and 0.77 by retest method.

3. The questionnaire of Rotter's locus of control: It was provided to assess the individual's generalized expectations of internal and external control of reinforcement.

It has 13 items which were developed by Rotter (1996). Its score range is 0-13.the low score indicates the internal locus of control and the high score indicates the external locus of control. The average of its reliability coefficients was calculated 0.7 by bisection and Kuder-Richardson methods.

\section{Data Analysis}

In this part, based on central tendencies, mean and standard deviation and also Pearson's correlation coefficient and regression and utilizing Spss software, the data were analyzed. 
Table1. Descriptive Statistics

\begin{tabular}{|c|c|c|c|c|c|}
\hline & N & Minimum & Maximum & Mean & Std. Deviation \\
\hline depres & 50 & 6 & 65 & 25.06 & 14.222 \\
approach & 50 & 4 & 51 & 26.42 & 12.736 \\
anxiety & 50 & 5 & 42 & 20.80 & 9.067 \\
emotion & 50 & 1 & 28 & 15.16 & 8.333 \\
total & 50 & 38 & 157 & 87.00 & 28.834 \\
n.a & 50 & 0 & 26 & 10.32 & 8.537 \\
p.s & 50 & 0 & 26 & 13.32 & 9.092 \\
D & 50 & 0 & 47 & 24.04 & 14.414 \\
locus & 50 & 0 & 13 & 5.74 & 4.222 \\
Valid N (listwise) & 50 & & & & \\
\hline
\end{tabular}

Table 2. Correlations

\begin{tabular}{|ll|c|c|c|c|}
\hline & & negative affectivity & social inhibition & type D personality & Locus of control \\
\hline \multirow{4}{*}{ depression } & Pearson Correlation & $0.380^{* *}$ & 0.165 & $0.329^{*}$ & 0.034 \\
& Sig. (2-tailed) & 0.006 & 0.252 & 0.020 & 0.815 \\
& $\mathrm{~N}$ & 50 & 50 & 50 & 50 \\
\hline \multirow{3}{*}{ positive attitudes drugs } & Pearson Correlation & 0.158 & 0.218 & 0.248 & -0.046 \\
& Sig. (2-tailed) & 0.272 & 0.128 & 0.082 & 0.752 \\
& $\mathrm{~N}$ & 50 & 50 & 50 & 50 \\
\hline \multirow{3}{*}{ anxiety } & Pearson Correlation & 0.172 & 0.003 & 0.148 & -0.235 \\
& Sig. (2-tailed) & 0.232 & 0.986 & 0.305 & 0.101 \\
& $\mathrm{~N}$ & 50 & 50 & 50 & 50 \\
\hline \multirow{3}{*}{ sensation seeking } & Pearson Correlation & 0.164 & 0.115 & 0.159 & 0.250 \\
& Sig. (2-tailed) & 0.256 & 0.427 & 0.271 & 0.080 \\
& $\mathrm{~N}$ & 50 & 50 & 50 & 50 \\
\hline \multirow{3}{*}{ addiction vulnerability } & Pearson Correlation & $0.354^{*}$ & 0.213 & $0.362^{* *}$ & 0.003 \\
& Sig. (2-tailed) & 0.012 & 0.138 & 0.010 & 0.985 \\
& $\mathrm{~N}$ & 50 & 50 & 50 & 50 \\
\hline \multirow{3}{*}{ Locus of control } & Pearson Correlation & 0.084 & 0.057 & 0.081 & 1 \\
& Sig. (2-tailed) & 0.562 & 0.694 & 0.578 & \\
& $\mathrm{~N}$ & 50 & 50 & 50 & 50 \\
\hline
\end{tabular}

*. Correlation is significant at the 0.05 level (2-tailed).

${ }^{*}$. Correlation is significant at the 0.01 level (2-tailed).

Table 3: Variables Entered/Removed ${ }^{\mathrm{b}}$

\begin{tabular}{|c|c|c|c|}
\hline Model & Variables Entered & Variables Removed & Method \\
\hline 1 & locus, $D^{a}$ & & Enter \\
\hline
\end{tabular}

a. All requested variables entered.

b. Dependent Variable: total

Table 4: Model Summary

\begin{tabular}{|c|c|c|c|c|}
\hline Model & R & R Square & Adjusted R Square & Std. Error of the Estimate \\
\hline 1 & $0.363^{\mathrm{a}}$ & 0.132 & 0.095 & 27.431 \\
\hline
\end{tabular}

a. Predictors: (Constant), locus, D 
Table 5: ANOVAb

Table 6: Coefficients ${ }^{\mathrm{a}}$

\begin{tabular}{|cc|c|c|c|c|c|}
\hline & Model & Sum of Squares & df & Mean Square & $F$ & Sig. \\
\hline \multirow{2}{*}{1} & Regression & 5373.243 & 2 & 2686.622 & 3.571 & $0.036^{\mathrm{a}}$ \\
& Residual & 35364.757 & 47 & 752.442 & & \\
& Total & 40738.000 & 49 & & & \\
\hline
\end{tabular}

a. Predictors: (Constant), locus, D

b. Dependent Variable: total

\begin{tabular}{|ll|c|c|c|c|c|}
\hline \multirow{2}{*}{ Model } & \multicolumn{2}{|c|}{ Unstandardized Coefficients } & Standardized Coefficients & \multirow{2}{*}{$\mathrm{t}$} & Sig. \\
\cline { 2 - 5 } & (Constant) & $\mathrm{B}$ & Std. Error & Beta & & \\
\hline \multirow{2}{*}{1} & 70.525 & 8.998 & & 7.838 & 0.000 \\
& $\mathrm{D}$ & 0.729 & 0.273 & 0.364 & 2.672 & 0.010 \\
& locus & -0.182 & 0.931 & -0.027 & -0.196 & 0.846 \\
\hline
\end{tabular}

a. Dependent Variable: total

\section{Discussion and Conclusion}

One of the issues that affects our community for years is addiction and what the conditions and causes create it. One of the most important factors is specific personality type. Our question in this study is "is there a specific personality type at the risk of addiction?". In this study, this question was studied. The results showed that there is a significant relationship between depression and type $\mathrm{D}$ personality. There is a negative relationship between the positive attitudes drugs abuse and internal locus of control and also between anxiety and fear and sensation seeking and internal locus of control. Addiction vulnerability has a positive and significant relationship with type D personality. Also, based on regression analysis and type $\mathrm{D}$ personality, individual's addiction vulnerability can be predicted and the internal locus of control has a reverse relationship with addiction vulnerability. This study's results are consistent with the researches of Polimeni and colleague (2010), Bond (2005), Ketabi et al. (2009), Gorgani (1990), Asarian, Omidi\&Sepehrmanesh et al. (2008), Cirakoglu et al.(2005), Zargar, Najarian\&Naemi (2008), Polimeni, Moore \&Gruenert (2010), Stefansson, Hesse (2008), Ball and collegue (2006), Meyer TD, Hoffman(2005), Kornor H, Nordvik (2007), McCrae \& Costa (2007), Lefcourt (1982), Almasi (1377) and Cheraghi (1389). In explaining these results, it can be discussed that people at high risk of addiction with stable tendency to experience negative emotions in different positions, experience more anxiety and panic and irritability than others. These moods, in turn, increase the frequency of type D personality in these patients. Also, people with external locus of control had a higher risk of addiction that can be led toward internal locus of control by training necessary skills and the probability of the increase of addiction vulnerability can be reduced by developing healthy personality types.

\section{References}

Almasi, A. (1377), "investigating and comparing the addicts' and non-addicts' locus of control", Master thesis, Tehran, Azad university of Rodehen.

Cheraghi, A. (1389), "The effect of group counseling with life skills training by approach Ellis's Rational Emotional approach on the locus of control and the change of students' attitudes towards drugs abuse", Proceedings Primary prevention of addiction, Tehran, Antidrug campaign.

Abolghasemi, A., Mahmoodi, H., \& Soleimani, A. (2009).The role of attachment styles and defensemechanisms in discriminating cigarette smoker students from non-smokers. J SabzevarUniv Med Sci, 16(3).Pp. 134-41.

Adrom, M., Nikmanesh, Z., Bakhshani, N.M. ( 2010).Prediction of addiction potential in youth according to personality trait. Proceeding of the Third Congress of Iranian PsychologicalAssociation.Pp.3-5.

Anisi, j., bahadori, M.H., Jahanbakhshi, M. (2013). Developing and Validation of identifying people in Risk of Addictionquestionnaire(I.P.R.A). Zahedan university of medical sciences Accepted in print.

Assarian, F., Omidi, A., Akbari, H.(2004). Psychological and personality characteristics of young addicted subjects in Kashan 2000. Feyz,vol. 8, NO.1,Pp. 37-42.

Bagherian,R\&bahrami,E.H.(2011).psychpmetric properties of the Persian version of type D personality scale (DS14).IJPBS.vol. 5, No.2,Pp.12-17.

Bahadorykhosroshahi, G., Khanjani, Z.(2011). The relationship between personality characteristics and attitude toward opiates. 
Proceeding of congress on the prevention of drug abuse.Azad University of Abhar branch.

Ball, S.A., Carroll, K.M., Canning-Ball, M.,\&Rounsaville, B.J.(2006). Reasons for dropout from drug abuse treatment: Symptoms, personality and motivation. Addict Behav,vol.31,Pp. 320-330.

Boles, S.M., Miotto, K.(2003). Substance abuse and violence: A review of the literature. Aggress Violent Behav, vol. 8,Pp.155-174.

Cirakoglu, O.C., Isin, G.(2005) Perception of drug addiction among Turkish university students: causes, cures, and attitudes. Addict Behav. Jan; 30(1): 1-8.

Denollet, J. (1998). "Personality and coronary heart disease: the Type-DScale DS-16". Annual Behavior Medicin,vol. 20,No.2,Pp. 209215

Emonsa, W., Mejier, R., Denollet, J. (2007). "Negative affectivity and social inhibition in cardiovascular disease: Evaluating type-D personality and its assessment using item response theory". Journal of Psychosomatic Research,vol, 63.Pp.27-39

Erickson, P.G.(1982). Illicit drug use, peer attitudes andperceptions of harmful effects among convicted cannabis offenders. Int J Addict,vol. 17,PP. 141-54.

Ghazinejad, M., Savalanpour, E.(2009).The relationship between social exclusion and addiction potential. J SocProbllran,vol. 16, No.3,Pp. 139-80.

Gorgani, T.(1990) Addiction and Personality. Tehran: Organization of Publications and Training Islamic Revolution.

Kaplan, H., Sadock, B.(2003). Synopsis of psychiatry. 9th ed. NewYork: Williams and Wilkins.

Ketabi, P., Maher, F., Borjaly, A.(2009).Identity and relationship addiction in women in Tehran province.Addic Studies,vol,2.No.3,Pp. 5469.

Kornor, H., Nordvik, H.(2007). Five-factor model personality traits in opioid dependence. BMC Psychiatry,Pp. 7- 37.

Lefcourt,H.m.(1982).locus of control: current trends in theory and Research(2nd).Hllsdale,Nj:Erlbum.

Logan, T.K., Walker, R., Cole, J.,\&Leukefeld, C.(2002). Victimization and substance abuse among women: Contributing factors, interventions, and implications.RevGenl Psychol,vol.6,Pp. 325-397.

Macdonald, S., Wells, S., Wild, T.C.(1999). Occupational risk factors associated with alcohol and drug problems. Am J Drug Alcohol Abuse,vol, 25.No.2,Pp.351-69

McCrae, R.R., Costa, P.C.(1987) Validation of the five-factor model across instruments and observers. J PersSocPsychol,vol. 52, Pp 8190.

McCann, S.J.(2005) Longevity, big five personality factors, and health behaviors: presidents from Washington to Nixon. J Psychol,vol,139.No.3,Pp. 273-86.

Meyer, T.D., Hoffman, B.U.(2005).Assessing the deregulation of the behavioral activation system: The hippomanic personality scale and the BIS-BAS Scales. JPersAssess,vol. 85,Pp. 318-324.

Najari, F.(2008). The evaluation of addiction in female addicts admitted to detoxification centers in Tehran during 2005 and 2006. J Med Counc I.R. Iran,vol.25,No.4,Pp. 457-62.

Nicholson, T., Higgins, C.W., Minors, P.,\& Price, J.O.(1996). A comparison of general health knowledge between American and Frenchspeaking Canadian college students: A pilot study. College Student J,vol. 30,No.1,Pp.141-143.2.

Polimeni, A.M., Moore, S.M., Gruenert, S.(2010). MMPI-2 profilesof clients with substance dependencies accessing a therapeutic community treatment facility. Electronic JAppPsychol,vol. 6,No.1,Pp. 1-9.

Roberts, R.E., Roberts, C.R., Xing, Y.(2007). Comorbidity of substance use disorders and other psychiatric disorders among adolescents: Evidence from an epidemiologic survey. DrugAlcohol Depend,vol. 88,No.1,Pp. 4-13.

Saah, T.(2005). The evolutionary origins and significance of drug addiction. Harm Reduct J,Pp.2- 8.

Salehi, M.(2001). Prediction of substance abuse relapses in relation of personality. Bull Iran Psych.Assoc,vol.2,No.3,Pp. 14-19.

Sarvela, P.D., McClendon, E.J.(1988). Indicators of rural youth drug use. J Youth Adolesc,Vol. 17,No.4,Pp. 335-347.

Sephrmanesh, Z., Ahmadvand, A., Ghoreyshi, F., Mousavi, G.A.(2008). Personality traits of IV drugabusers of Kashan prison. Feyz,Vol. 12,No.1,Pp. 69-75.

Stefansson, R., Hesse, M.(2008). Personality disorders insubstance abusers: A comparison of patients treated in a prison unit and patients treated in inpatient treatment. IntJMent Health Addic,vol. 6,Pp.402-406.

Terracciano, A., Costa, P.T.(2004).Smoking and the Five-Factor Model of personality.Addiction. Vol. 99,No.4,Pp.72-81.

Walton, K.E., Roberts, B.W.(2004). On the relationship between substance use and personality traits: Abstainers are not maladjusted. J Res Pers, Vol. 38,Pp. 515-535.

Weijers, H.G., Wiesbeck, G.A., Wodarz, N., Keller, H., Michel, T., Boning, J. (2003). Gender and personality in alcoholism. Arch WomensMentHealth, Vol. 6, No.4, pp. 245-52. 